\title{
GESTIÓN ORGANIZACIONAL. HACIA UNA \\ VERDADERA TRANSFORMACIÓN, SUPERVIVENCIA Y \\ COMPETITIVIDAD
}

El mundo empresarial global viene experimentando cambios económicos, sociales, políticos, culturales y tecnológicos que se acentúan aún más en escenarios de pandemia por la COVID-19 a partir del año 2020; lo cual exige respuestas oportunas e inmediatas por parte de quienes lideran las organizaciones con el propósito de generar flexibilidad, capacidad de adaptación, supervivencia y competitividad de manera saludable, por lo que se hace necesario el desarrollo de propuestas disruptivas, novedosas y viables que permitan dar respuestas a las distintas problemáticas que se presentan en el mercado mundial. Dichos cambios y transformaciones actuales alteran la naturaleza y el curso futuro de la sociedad, ejerciendo un impacto significativo sobre todos los aspectos de la vida e incrementando al mismo tiempo la necesidad de agilizar la ejecución de los procesos en general.

En este orden de idea, el ámbito empresarial enfoca sus esfuerzos en buscar mecanismos de orden sistemáticos que garanticen de manera efectiva la gestión de personas y de los procesos organizacionales, promoviendo mejoras, creando espacios colaborativos propicios para el autodesarrollo y, en consecuencia, lograr los resultados deseados. En este sentido, se presenta la gestión organizacional como un mecanismo que permite al sector empresarial planificar las acciones que contribuyan al funcionamiento de éste a través de la realización y cumplimiento de tareas, metas y objetivos trazados por la organización con la intención de alcanzar resultados positivos y rentables.

Cabe destacar que la gestión organizacional ha brindado aportes para alcanzar el éxito en el sector empresarial, esto se debe a la capacidad de desarrollo involucrando tanto los procesos productivos como a sus miembros. Por tal razón, es considerada la clave para crear prosperidad y éxito empresarial, ya que tiene el potencial de generar la competitividad en las organizaciones dando lugar de esta forma al 
crecimiento y al desarrollo en los ambientes macroeconómicos, institucional y jurídico.

Por todo lo anterior, se puede inferir que la gestión organizacional tiene un papel protagónico en el desempeño empresarial y en las unidades funcionales que la componen generando modificaciones en sus estructuras organizacionales, en los avances tecnológicos, en los procesos comunicacionales, en la cultura y por ende en la forma de liderar, impulsando su capacidad de influir, persuadir y motivar a los seguidores ante las necesidades de cambio, trayendo como consecuencia que las empresas se vean presionadas a implementar transformaciones para adaptarse adecuadamente a las exigencias de los mercados altamente competitivos.

Por consiguiente, la gestión organizacional permite definir qué acciones estratégicas se deben diseñar y ejecutar para obtener resultados óptimos y favorables, teniendo en cuenta que la competitividad juega un papel fundamental en el sector empresarial, porque les permite mantenerse en el mercado, proporcionándoles el alcance de los objetivos, productividad, sostenibilidad y crecimiento económico.

Es importante resaltar que la empresa es un sistema donde convergen diversos recursos (humanos, financieros, tecnológicos y físicos), no se puede pasar por alto que las personas son la única fuente de ventaja competitiva sostenible en un mundo con alta complejidad. Las organizaciones están seguras de que el camino al éxito radica en la inteligencia y el conocimiento de las personas. Por ello, los líderes que logren explorar y desarrollar el potencial del individuo, y de generar un desempeño superior, lograrán mantenerse en un entorno de alta competencia.

Para concluir, se puede afirmar que el éxito en la gestión organizacional dependerá de la forma como los gerentes asimilen y manejen la información y sus procesos, reconocer el espectro organizacional es vital para cualquier líder, precisar objetivos y estrategias; definir un modelo organizacional acorde con la realidad de la organización, medir el desempeño de los procesos a través de un modelo 
de gestión por indicadores le garantizara un control dinámico y la implementación de acciones de mejora de manera oportuna; lo que garantiza la consecución de resultados favorables y sostenibles para la organización.

\section{Dr. Ronald Prieto Pulido}

Decano de la Facultad de Administración y Negocios

Universidad Simón Bolívar, Colombia

Prieto Pulido, R. (2021). Gestión organizacional. Hacia una verdadera transformación, supervivencia y competitividad. SUMMA. Revista disciplinaria en ciencias económicas y sociales, 3(2), 1-3. DOI: www.doi.org/10.47666/summa.3.2.21 